\title{
Daniela Marino. Huixquilucan. Ley y justicia en la modernización del espacio rural mexiquense, 1856-1910. Madrid: Consejo Superior de Investigaciones Científicas, Estudios Americanos, Tierra Nueva, 2016, 269 p. ISBN 978-84-00-10081-0
}

\section{Paulina Ultreras Villagrana}

UNIVERSIDAD DE GUADALAJARA, CUTONALÁ, paultreras@yahoo.com.mx

$\mathrm{E}$ 1 libro de Marino, publicado en la colección maior de Estudios Americanos del csic, denominada Tierra Nueva, aclara y abre nuevas líneas de investigación sobre el siglo xIx mexicano, en particular, en la historia social del derecho y el proceso de desamortización de tierras en el Estado de México.

Daniela Marino recorre los laberintos de la justicia mexicana del siglo XIX, tomando como eje el ahora municipio de Huixquilucan, el objeto de estudio "son las transformaciones sociales, políticas y económicas de un municipio del centro de México en relación con dichas políticas estatales" (p. 20). Aunque el libro abarca el siglo xIx, éste es dividido en dos etapas: 1) la primera mitad del siglo XIX, hasta 1856, con el fin de poner en contexto el lugar de estudio y los cambios en la legislación bajo el espíritu liberal desde fines del periodo colonial; 2) de 1856 a 1910, desde la promulgación de la Ley Lerdo con la que inicia la individualización de tierras comunales hasta el inicio de la Revolución mexicana, haciendo hincapié en el Segundo Imperio y la República. La investigación, fruto de su tesis doctoral, explica la igualdad jurídica y el monopolio del derecho en una sociedad diversa, aunque mayoritariamente indígena, frente a una cultura jurídica hegemónica en la que los pueblos surcaron por los cambios legislativos del siglo XIX retomando discursos coloniales mezclados con los de la época y apelando a los recursos legales a su alcance.

El libro de Marino retoma uno de los temas más descuidados en la historiografía mexicana: la desamortización de bienes civiles. ${ }^{1}$ La ex-

${ }^{1}$ Si bien se han hecho grandes avances al respecto, aún nos queda largo camino por recorrer, especialmente en los estudios de caso. Algunos trabajos sobresalientes son los de Margarita Menegus, Antonio Escobar Ohmstede, Romana Falcón, Raymond Buve, Frank Schenk, Jennie Purnell, Michael Ducey, entre otros. Además de los señeros textos de Andrés Molina Enríquez, Wistano Luis Orozco o Moisés González Navarro. 
haustiva revisión de los códigos legales y sus modificaciones, contradicciones y consecuencias en un pueblo del Estado de México es una particularidad loable de la obra. Además del estudio detallado de los códigos legales, Marino consultó distintos archivos nacionales, locales, hemerotecas y fototecas. Su libro se inscribe en la nueva historia social y cultural del derecho y la justicia, en la cual no sólo se presta atención a las leyes, sino a las prácticas de los pueblos para encarar las nuevas disposiciones por lo que presenta una metodología clara y fuentes acordes al tema señalado.

Los pueblos indígenas en el periodo colonial poseían una amplia cultura jurídica y acudían de manera colectiva a los tribunales para resolver sus conflictos. La justicia formaba parte de la cultura de los pueblos en el siglo XIX y constituye el punto de partida de Marino. La autora analiza los cambios jurídicos en el municipio con respecto a la tenencia de la tierra; la participación de los indígenas para negociar dichos cambios; la incorporación de un nuevo marco jurídico; y las distintas estrategias empleadas por los pueblos para denunciar las acciones del gobierno o de los particulares con respecto a las tierras y los recursos naturales.

Huixquilucan era un pueblo de indios mayoritariamente habitado por otomíes. La fisiografía del terreno: boscoso y montañoso, permitía la explotación de leña y carbón que eran comercializados en la Ciudad de México, mientras que una menor cantidad de pobladores se dedicaban a la producción de pulque. Debido a que los productos que se producían no tenían amplia demanda, la autora demuestra que el interés por concretar la desamortización provino de los propios vecinos y los marcos jurídicos contribuyeron a tal hecho, pues, se excluyó a los actores colectivos de la nación.

Los cuatro capítulos que comprende la obra sumergen al lector en la dinámica del municipio, se detallan las características naturales, demográficas, económicas y sociales, pasando por los procesos históricos que permitieron a los mestizos controlar el municipio. Un aspecto central es el análisis de las nociones de justicia que poseían los pueblos indígenas, éstas son estudiadas a través de los recursos de apelación en los niveles estatal y federal.

Después de la independencia y con la erección de los municipios, Huixquilucan fue controlado por un ayuntamiento mestizo, la repre- 
sentación indígena quedó a nivel de barrio, pero se defendieron de manera colectiva durante el siglo xIx. Para la autora, si bien, la competencia por los recursos naturales, como la tierra y el agua, fue el malestar de los indígenas, el conflicto se trasladó al ámbito municipal, pues, la legislación electoral después de 1824 delineaba criterios económicos y de alfabetización para poder ocupar un cargo municipal, por lo tanto, se desplazó a los indígenas de los puestos municipales y por ańadidura del control sobre los propios y arbitrios, ya que a nivel estatal los ayuntamientos tuvieron permiso para litigar asuntos de tierras en el ámbito federal. Como municipio pluriétnico, los vecinos, junto con los indígenas, a finales del siglo XIX, promovieron juicios colectivos para desamortizar terrenos comunales y participar en su reparto. La autora considera que el ayuntamiento, más que el jefe político, los gobernadores indígenas o los jueces auxiliares, como sucedía en otros sitios, fue fundamental en las disputas de terrenos comunales; eran las autoridades municipales las que trataban de conciliar entre los querellantes.

En el segundo capítulo se explican las relaciones entre el naciente ayuntamiento y la población, así como los decretos en torno a la desamortización de bienes y los terrenos que pasaron a la administración del ayuntamiento (los terrenos del común o propios). La legislación es cuidadosamente estudiada en el periodo que corre de 1825 a 1910, dando detalle de las afectaciones a nivel municipal y la respuesta de los indígenas, con el objetivo de explicar el proceso de desamortización. En el estado de México fue hasta la restauración de la República, a finales de la década de 1860, cuando las autoridades municipales se interesaron en poner en marcha el proceso desamortizador "a fin de conseguir recursos para cubrir el déficit de las finanzas municipales” (p. 116). Los pueblos estudiados por Marino: San Francisco y Santa Cruz Ayotuxco, a principios de 1880, administraban los recursos de los propios, poseían terrenos de comunidad, ejidos y propios. A fin de llevar a cabo el proceso hubo litigios entre vecinos y pueblos, la ley favoreció a los primeros por lo que se desató la violencia y la resistencia: oposición a la autoridad, apelaciones legales, invasión de terrenos, tumultos, etcétera.

El capítulo tres profundiza en las transformaciones de la cultura jurídica en relación con la ampliación socioétnica del ex pueblo de indios y las ventajas de los nuevos vecinos al conseguir los beneficios que 
les otorgó el estatus de vecindad. La justicia y el derecho escrito fueron los protagonistas en la resolución de conflictos, en este periodo se profesionaliza el derecho y se suplantan jueces legos por letrados, además se adaptan las nuevas fórmulas del discurso liberal. En este capítulo la autora estudia, a través del juzgado conciliador, los litigios promovidos por los indígenas y los cambios en la legislación a partir de la ley Lerdo, la Constitución de 1857, la Ley agraria del Segundo Imperio, la Ley de 26 de marzo de 1894, la revisión del artículo 27 constitucional de 1901 y la Constitución Federal de 1917. Los cambios en la legislación obstaculizaron la puesta en práctica de la desamortización y se presentaron casos en la Suprema Corte, por lo cual, con ejemplos concretos, Marino muestra las resoluciones y visiones de jueces como Vallarta y Moreno Cora.

En el Segundo Imperio (aunque vigente la Ley Lerdo) se incrementaron las peticiones y los expedientes encontrados en la Junta Protectora de Clases Menesterosas son analizados en el cuarto capítulo. Durante el Segundo Imperio existió una política de atención a los indígenas y éstos presentaban mociones formales frente al emperador y su esposa para recuperar sus tierras. Marino examina el discurso utilizado en las peticiones y hace dos distinciones: aquellas presentadas por un abogado ajeno a la comunidad que utiliza un lenguaje elaborado; y aquellas presentadas por los personajes locales en donde se muestran menor número de reverencias e introducen fórmulas de la nueva cultura política.

La obra de Marino representa un serio esfuerzo por comprender la historia social y cultural del derecho en un periodo de importantes cambios políticos. La historia social del derecho debe entenderse desde distintas aristas, como hace la autora, incluyendo la dimensión social, económica, política y cultural. Así, si bien se estudia un municipio del Estado de México, estado que ha obtenido gran atención por parte de los historiadores, ${ }^{2}$ no teníamos aún un trabajo que se enfocara en la

${ }^{2}$ Recordemos los significativos avances que han realizado Romana Falcón, Historia desde los márgenes: senderos hacia el pasado de la sociedad mexicana (México: El Colegio de México, 2011). Diana Birrichaga, "El arrendamiento de los propios de los pueblos en el Estado de México, 1824-1835”, en A la sombra de la primera república federal. El Estado de México, 1824-1835, coord. María del Pilar Iracheta y Diana Birrichaga, 313-328 
argumentación jurídica de los miembros de los extintos pueblos indígenas y las implicaciones, en la esfera municipal, de los cambios legislativos federales y estatales, por lo que el libro es imprescindible para el conocimiento del México decimonónico.

(México: El Colegio Mexiquense). Gloria Camacho Pichardo, "Desamortización y reforma agraria en Ocoyoacac y Lerma, 1856-1930, en Agua y tierra en México, siglos XIX y XX, tomo I, coord. Antonio Escobar Ohmstede, Martín Sánchez y Ana María Gutiérrez, 287-310 (México: El Colegio de Michoacán, El Colegio de San Luis), entre otros. 